\title{
Electrochemical Reaction Characteristics of Halide- Halate-Acid Systems for Amperometric Detection of Acid
}

\author{
Katsuo TAKAHASHI ${ }^{*}$, Fumie TAKEI $^{\dagger}$ and Toru ISHIJI ${ }^{\dagger}$ \\ Received April 6, 1995 ; Accepted May 29, 1995
}

\begin{abstract}
Acid sensitive cathodic reactions in halate and halide-halate solutions were investigated by polarography to characterize the reactions for an amperometric acidic-gas sensing. The polarographic limiting current, $I_{\mathrm{d}}$, is proportional to the amount of added acid into bromate and iodate solutions, which is attributed to the electrode reaction of $\mathrm{XO}_{3}^{-}+6 \mathrm{H}^{+}+6 \mathrm{e}^{-} \rightarrow \mathrm{X}^{-}+3 \mathrm{H}_{2} \mathrm{O}(\mathrm{X}=\mathrm{Br}$ or $\mathrm{I})$, whose current is controlled by diffusion of the hydrogen ions. Iodine is liberated from $\mathrm{KI}+\mathrm{KIO}_{3}$ solutions with addition of acid. The reduction current of the iodine showed good linearity to the amount of added acid. The effect of alkaline additive in $\mathrm{KI}+\mathrm{KIO}_{3}$ solutions on the liberation of iodine was discussed as competitive reactions between the neutralization and the iodine liberation.
\end{abstract}

\section{INTRODUCTION}

Some amperometric sensors for detection of acidic gases have been practically used for industrial and environmental measurements and monitoring. For the commercially available amperometric sensors, electrochemical reductions of platinum oxide, iodine, iodate, and bromine have been used as an acid sensitive cathodic reaction on a gas permeable membrane electrode ${ }^{1-3}$ ). The concentration of an acidic gas in the atmosphere is well detected by the sensors involving these cathodic reactions under particular conditions, however, the reaction characteristics have not been cleared because of complications of composition of the sensor

The Institute of Physical and Chemical Research(RIKEN), (Wako-shi, Saitama 351-01, Japan)

+ Institute of Scientific and Industrial

Research, Osaka University, (Ibaraki-shi, Osaka-fu 567, Japan)

+ Riken Keiki Co. Ltd., 2-7-6 Azusawa, (Itabashi-ku, Tokyo 174, Japan)

Key words: acid sensitive cathodic reactions, polarography, halates, iodine liberation solutions and of reaction mechanisms at the gas-solution-electrode interface of the sensors.

In this study, the electrochemical reactions induced by added acid in halide-halate and halate solutions were investigated by polarography to elucidate the reaction characteristic and mechanisms, and to choose superior condition of the sensor solutions.

As is well known reaction system of iodideiodate-acid, the reaction has been represented by equations(1) and (2) 4-6):

$$
\begin{array}{ll}
\mathrm{IO}_{3}^{-}+5 \mathrm{I}^{-}+6 \mathrm{H}^{+} \rightarrow 3 \mathrm{I}_{2}+3 \mathrm{H}_{2} \mathrm{O} & --(1) \\
\mathrm{I}_{2}+2 \mathrm{e}^{-} \rightarrow 2 \mathrm{I}^{-} & --(2)
\end{array}
$$

Since the amount of liberated iodine is proportional to that of added acid(eq.(1)), the acid amount can be determined from the reduction current of the liberated iodine(eq.(2)). In this paper, the iodine, $\mathrm{I}_{2}$, means dissolved $\mathrm{I}_{2}$ as $\mathrm{I}_{3}^{-}$, because excess amount of $\mathrm{I}^{-}$coexists in the solutions.

Although it has been mentioned that halogens are liberated from the halide-halate-acid solutions ${ }^{4)}$, the liberation of halogens except the iodine were not observed in our experimental conditions. However, it is observed that the polarographic reduction current clearly 
depends on the amount of acid added into the halide-halate and the halate solutions. It is important to compare the reaction properties of the halide-halate-acid systems of different halogens to reveal the cathodic current charcteristics depending on the amount of added acid.

It has been appointed out that the alkaline additive is useful to stabilize the iodide-iodate solution as used for a sensor-electrolyte ${ }^{3)}$. In this paper, the effect of alkaline additive on the iodine liberation induced by the added acid is also discussed as competitive reactions between the iodine liberation and the alkalineacid neutralization.

\section{EXPERIMENTAL}

All electrolytic solutions were prepared by commercially available reagent grade chemicals and redistilled water. The sample solutions in a cell were dearated by nitrogen gas bubbling before electrachemical measurements. Proper amounts of 0.1 or $1 \mathrm{M}\left(\mathrm{M}=\mathrm{mol} \mathrm{dm}^{-3}\right)$ acid were added by a microcylinge into $50 \mathrm{~cm}^{3}$ of the solution in the cell.

A conventional three electrode cell system composed by a dropping mercury electrode (DME), a saturated calomel electrode(SCE), and a Pt wire electrode was used for electrochemical measurements. The dropping time of DME was mechanically controlled to $4.0 \mathrm{~s}$. The mercury flow rate was $0.83-0.86 \mathrm{mg} \mathrm{s}^{-1}$.

To determine the iodine concentration liberated by the added acid in $\mathrm{KI}^{-} \mathrm{KIO}_{3}-\mathrm{KOH}$ solutions, conventional dc polarography and a constant potential method were utilized. On the latter method, the time dependence of the polarographic limiting current for iodine reduction was recordled by a pen-recorder at the constant potential $-0.7 \mathrm{~V}$, to extrapolate the current immediately after the injection of $\operatorname{acid}\left(0.1 \mathrm{M} \mathrm{HCO}_{4}\right)$ into the solution by a microcylinge. The slow current decay being less than $10 \%$ per minute was observed, which was attributed to a slow reaction of iodine in an alkaline medium ${ }^{7}$,

$$
\mathrm{I}_{2}+2 \mathrm{OH}^{-} \rightarrow \mathrm{IO}^{-}+\mathrm{I}^{-}+\mathrm{H}_{2} \mathrm{O}
$$

however, this reaction process is not a subject in this paper.

\section{RESULTS}

Figures 1 - 3 show polarograms for solutions whose compositions are listed in table 1 . Characteristic values of the polarograms, halfwave potential, $E_{1 / 2}$, and the limiting current, $I_{\mathrm{d}}$, are also shown in the table, where $I_{\mathrm{d}}$ is obtained by subtraction of the residual current from the observed limiting current. The concentrations of the electrolytes, A and $\mathrm{B}$, as shown in the table, are 0.125 and $0.025 \mathrm{M}$, respectively, which are chosen to compare the halide-halate systems and the indifferent salthalate systems. The concentration ratio of $[A] /[B]=5$ is due to stoichiometric ratio of the reaction (1). The concentration changes of $A$ and $B$ in suitable concentration region $([B]>>$ $\left.\left[\mathrm{H}^{+}\right]\right)$do not influence the polarographic behavior induced by the added acid.

Figure 4 shows relationship between $I_{\mathrm{d}}$ and the amount of added acid as indicated by molar concentration in the sample solution, [acid], for typical electrolytic solutions. Good linear relations are obtained. The relationship between $I_{\mathrm{d}}$ and [acid] is also shown in Fig. 5 for the addition of weak acids.

The effects of alkaline additive on $I_{\mathrm{d}}$ as a function of [acid] are shown in Fig. 6.

The liberated iodine concentrations induced by the addition of $\mathrm{HClO}_{4}$ in the solutions containing various concentrations of the electrolytes, $[\mathrm{KI}],\left[\mathrm{KIO}_{3}\right]$ and $[\mathrm{KOH}]$, are plotted in Fig. 7 as functions of their concentrations, $c \mathrm{el}$.

\section{DISCUSSION}

\subsection{Bromate systems}

Polarograms (curves 7, 8, 9, 14, and 15 in Figs. 1 and 2) show the cathodic reaction of bromate represented by eq. (4),

$$
\mathrm{BrO}_{3}^{-}+6 \mathrm{H}^{+}+6 \mathrm{e}^{-} \rightarrow \mathrm{Br}^{-}+3 \mathrm{H}_{2} \mathrm{O} \quad--(4)
$$

whose reaction property has been analyzed by 


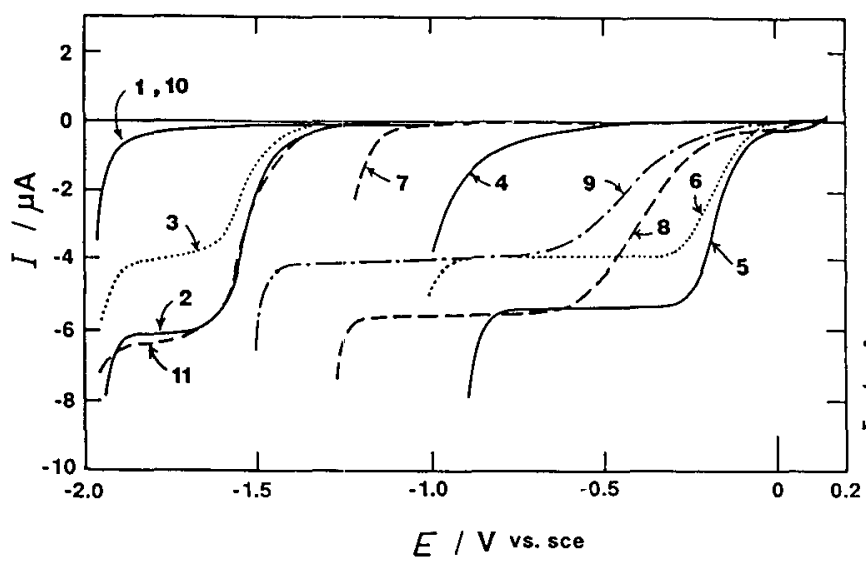

Fig. 1 Polarograms for supporting electrolyte - halate solution systems. Compositions are listed in table 1.
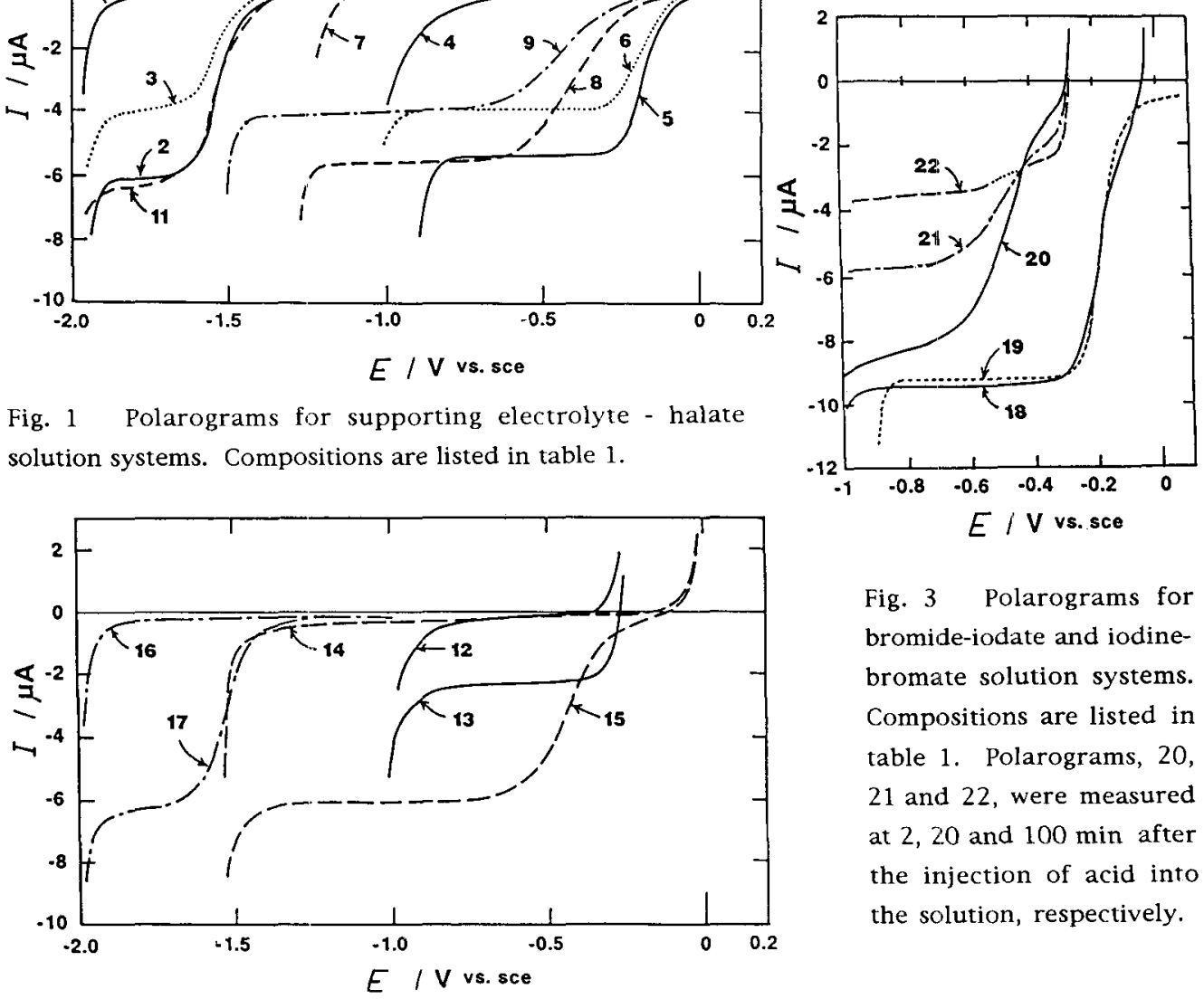

Fig. 3 Polarograms for bromide-iodate and iodinebromate solution systems. Compositions are listed in table 1. Polarograms, 20, 21 and 22 , were measured at 2, 20 and $100 \mathrm{~min}$ after the injection of acid into the solution, respectively.

Fig. 2 Polarograms for halide - halate solution systems.

Compositions are listed in table 1.

Orlemann and Kolthoff ${ }^{8)}$.

In the neutral solutions(curves 7 and 14), the bromate is reduced at the potentials more negative than $-1 \mathrm{~V}$ because of its high overpotential. The reduction wave shifts to more positive potential domain in the acidic solutions (curves 8,9 and 15 ), which have $E_{1 / 2}=$ $-0.45 \mathrm{~V}$ and $I_{\mathrm{d}} /\left[\mathrm{HClO}_{4}\right]=-10 \mu \mathrm{A} \mathrm{mM}^{-1}$ in the bromate-perchlorate and bromate-bromide solutions and $I_{\mathrm{d}} /\left[1 / 2 \mathrm{H}_{2} \mathrm{SO}_{4}\right]=-6 \mu \mathrm{A} \mathrm{mM} \mathrm{m}^{-1}$ in the bromate-sulfate solution. In such systems, $I_{\mathrm{d}}$ is directly proportional to the added acid concentration, [acid], and $I_{\mathrm{d}}$ 's are similar to $I_{\mathrm{d}}$ of the hydrogen ion reduction in the supporting electrolyte solutions(see curves 2 and 3 ). The reduction wave has been attributed to the bromate reduction controlled by the diffusion of hydrogen ions consumed with the reaction of eq. $(4)^{8)}$. I $I_{\mathrm{d}}$ in the sulfate solutions is lower than that in the perchlorate and bromide solutions, which can be due to the concentrations of dissociated hydrogen ions predicted from the dissociation constants of acids. No bromine liberation (no color change and no reduction wave of bromine, $\mathrm{Br}_{2}+2 \mathrm{e}^{-} \rightarrow 2 \mathrm{Br}^{-}$) was observed for $\mathrm{Br}^{-}+\mathrm{BrO}_{3}^{-}+\mathrm{H}^{+}$system.

\subsection{Chlorate systems}

No reduction wave appeared for neutral $\mathrm{ClO}_{3}^{-}$ solutions in a conventional polarographic potential window as shown by the curves 10 and 16 in Figs. 1 and 2. 
Table 1 Compositions of the electrolytic solutions for polarograms shown in Figs. 1-3, and their half-wave potentials, $E_{1} / 2$, and limiting current values, $I_{\mathrm{d}}$.

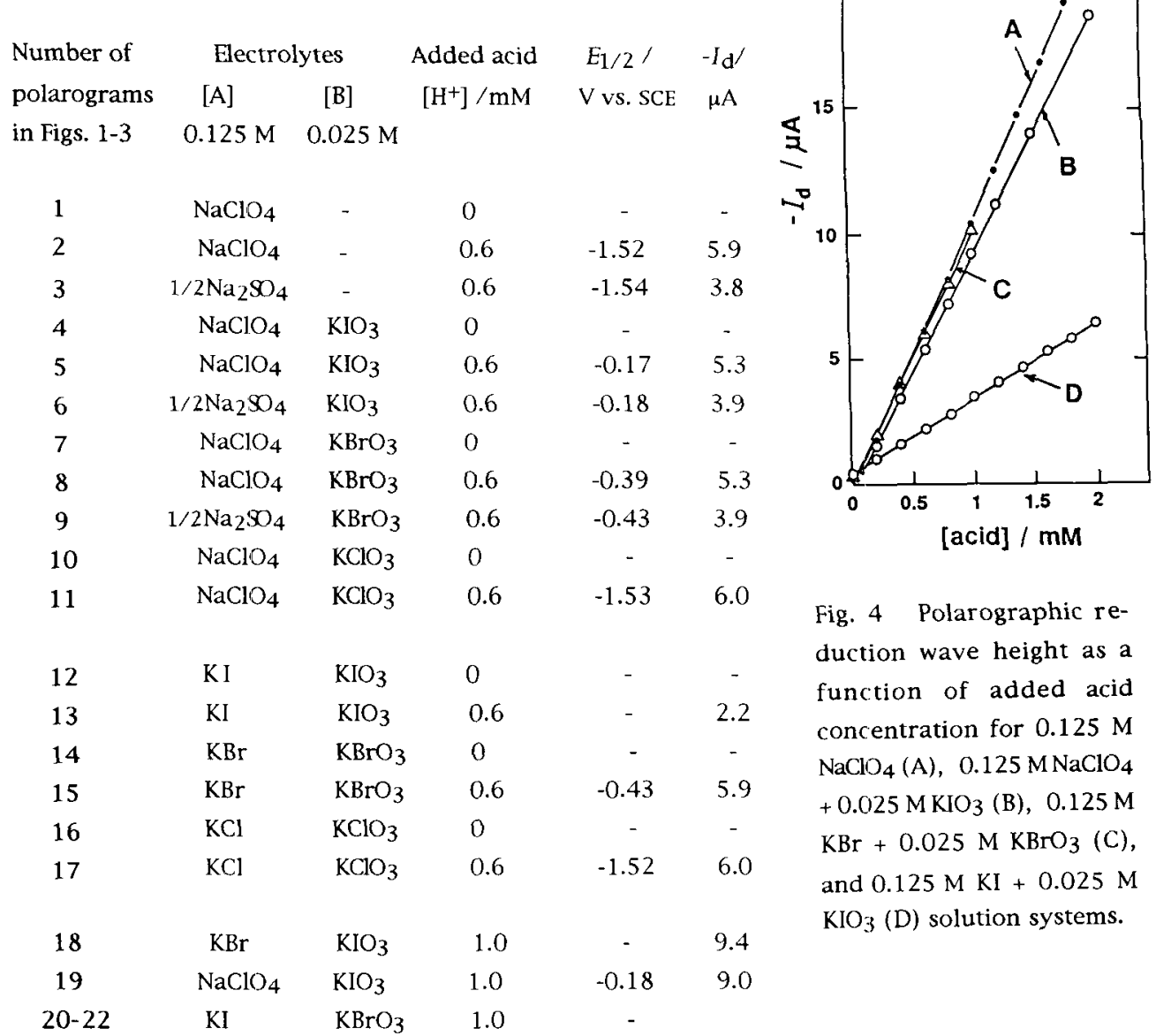

In the acidic $\mathrm{ClO}_{3}^{-}$solution, a reduction wave appears on the curves 11 and 17 in Figs. 1 and 2 , which is assigned to be $\mathrm{H}^{+}$reduction because of the good agreement of the curves 11,17 and 2. No chlorine liberation was observed in $\mathrm{Cl}^{-}+$ $\mathrm{ClO}_{3}^{-}+\mathrm{H}^{+}$solution.

\section{3 lodate systems}

The polarograms, curves $4,5,6,12$ and 13 in Figs. 1 and 2, show the cathodic reduction properties of iodate solutions.

It is well known that the iodine is liberated from an iodide-iodate solution with addition of acid, whose reaction has been represented by eq. $(1)^{4)}$. The iodide-iodate solution becomes red-brown color with addition of acid. The polarogram and a visible spectrum of the solution agree with those of an aqueous solution of iodine $\left(\mathrm{I}_{3}^{-}\right)$. From these results, the reduction wave on curve 13 in Fig. 2 at the potential domain $-0.4--0.8 \mathrm{~V}$ is attributed to the reduction of iodine liberated by the added acid, as represented by eq. $(2)^{5,6)}$. The $I_{\mathrm{d}}$ is about one third of that of $\mathrm{BrO}_{3}^{-}$or $\mathrm{H}^{+}$ reduction, which is due to difference between diffusion coefficient of the iodine and that of the hydrogen ion.

In cases of $\mathrm{ClO}_{4}^{-}+\mathrm{IO}_{3}^{-}+\mathrm{H}^{+}$and $\mathrm{SO}_{4}{ }^{-}+\mathrm{IO}_{3}^{-}$ $+\mathrm{H}^{+}$systems, no color change and no reduction wave of $I_{2}$ were observed with addition of acid, which suggest that no liberation reaction of iodine occurs in these systems. The reduction waves appear with addition of acid, as shown in Fig. 1 curves 5 and 6 , which is not attributed to 
the reduction of iodine but that of iodate as is represented by eq. (5), whose reaction rate is controlled by the diffusion of the hydrogen ions.

$$
\mathrm{IO}_{3}^{-}+6 \mathrm{H}^{+}+6 \mathrm{e}^{-} \rightarrow \mathrm{I}^{-}+3 \mathrm{H}_{2} \mathrm{O} \quad---(5)
$$

\subsection{Halide-halate systems}

Since there is a significant difference between reactions of $\mathrm{Br}^{-}+\mathrm{BrO}_{3}^{-}+\mathrm{H}^{+}$and $\mathrm{I}^{-}+$ $\mathrm{IO}_{3^{-}}+\mathrm{H}^{+}$systems, we measured the polarograms of the systems involving different halogen combinations, $\mathrm{X}^{-}+\mathrm{YO}_{3}^{-}+\mathrm{H}^{+}$.

The solutions containing chlorate showed no reduction wave except the $\mathrm{H}^{+}$-reduction. For the acidic solutions of $\mathrm{Cl}^{-}+\mathrm{BrO}_{3}^{-}, \mathrm{Cl}^{-}+\mathrm{IO}_{3}^{-}$, and $\mathrm{Br}^{-}+\mathrm{IO}_{3}^{-}$, the reduction waves correspond to each halate reduction wave and no color change were observed with addition of acid. The polarograms of $\mathrm{Br}^{-}+\mathrm{IO}_{3}^{-}+\mathrm{H}^{+}$and $\mathrm{ClO}_{4}^{-}+$ $\mathrm{IO}_{3^{-}}+\mathrm{H}^{+}$systems are shown in Fig. 3, indicating that the same $\mathrm{IO}_{3}{ }^{-}$-reduction proceeds in both solutions. These results suggest that no halogen liberation reaction is induced by the addition of acid in these solutions. The halides behave as an indifferent salt in the solutions.

The other hand, the color of $\mathrm{I}^{-}+\mathrm{BrO}_{3}^{-}$ solution gradually changed from yellow to brown after the addition of acid. The polarograms of 20-22 in Fig. 3 for $\mathrm{I}^{-}+\mathrm{BrO}_{3}^{-}+\mathrm{H}^{+}$ system show changing of the polarogram with time from the bromate reduction wave to the liberated-iodine reduction wave. Such slow iodine liberation mechanism has been proved by Barton and Wright ${ }^{9}$, and Indelli et al. ${ }^{10}$ ).

\subsection{Effect of weak acid}

The effect of proton dissociation on the wave height of halate reduction has been mentioned in 4.3. To clear the dissociation effect on the halate-reduction and iodine-liberation reactions, the polarograms were measured for $\mathrm{NaClO}_{4}+\mathrm{KIO}_{3}$ and $\mathrm{KI}+\mathrm{KIO}_{3}$ solutions with addition of weak acids, HA.

The wave shapes $\left(E_{1 / 2}\right)$ with addition of weak acids is similar to those of systems added a strong acid. The relationship between the limiting current, $I_{\mathrm{d}}$, and added acid concen- tration, [HA], is shown in Fig. 5.

In the case of iodate-reduction $\left(\mathrm{NaClO}_{4}+\mathrm{KIO}_{3}\right.$ system), the slope significantly depends on the sort of added acid. The limiting current is controlled by diffusion of $\mathrm{H}^{+}$and $\mathrm{HA}$ in the solution, so that lower $I_{\mathrm{d}}$ is obtained for the weak acid. The $I_{\mathrm{d}}$ observed can be approximately predicted from dissociation constant of acids and diffusion constants of $\mathrm{H}^{+}$and $\mathrm{HA}$.

In contrast, the $\mathrm{KI}+\mathrm{KIO}_{3}$ systems give same $I_{\mathrm{d}}$ for the addition of $\mathrm{HClO}_{4}$ and acetic acid. It suggests that the iodine liberation is proceeded by protons supplied from both dissociated and associated weak acid in the solution.

4.6 Effect of alkaline additive on the iodine liberation

Figure 6 shows the effects of alkaline additive on $I_{\mathrm{d}}$ as a function of added acid concentration.

In the case of $\mathrm{NaClO}_{4}+\mathrm{KIO}_{3}+\mathrm{KOH}+\mathrm{HClO}_{4}$ system, the relationship between $I_{d}$ and [acid] is linear for $[\mathrm{KOH}]=0$, as shown by plot $\mathrm{A}$ in Fig. 6(a), whereas the reduction current appears when [acid] becomes higher than $[\mathrm{KOH}]$ in the solution containing $\mathrm{KOH}$ (plot $\mathrm{B}$ ). It suggests that a simple neutralization proceeds in the solution, so that the $\mathrm{H}^{+}$concentration is determined by the added acid and alkaline concentrations, [acid] - $[\mathrm{KOH}]$. Then $I_{\mathrm{d}}$ is determined by the $\mathrm{H}^{+}$concentration in the sample solution according to eq.(5).

The other hand, $\mathrm{KI}+\mathrm{KIO}_{3}+\mathrm{KOH}+\mathrm{HClO}_{4}$ systems give linear relationships on $I_{\mathrm{d}}$-[acid] plot, where $I_{\mathrm{d}}$ is attributed to the reduction of liberated iodine. Although the slope of $I_{\mathrm{d}^{-}}$ [acid] relation decreases with increase of $[\mathrm{KOH}]$, the seemingly linear relation suggests that the neutralization and the iodine liberation proceed competitively after the addition of acid in the solution.

To characterize the competitive reaction, the concentration of iodine, $\left[\mathrm{I}_{2}\right]$, liberated with addition of $1 \mathrm{mM} \mathrm{HClO}_{4}$ is plotted as functions of the concentrations of electrolytes, $[\mathrm{KI}],\left[\mathrm{KIO}_{3}\right]$, and $[\mathrm{KOH}]$, as shown in Fig. 7. The figure shows that the higher [KI] gives higher iodine liberation, the higher [KOH] remarkably 


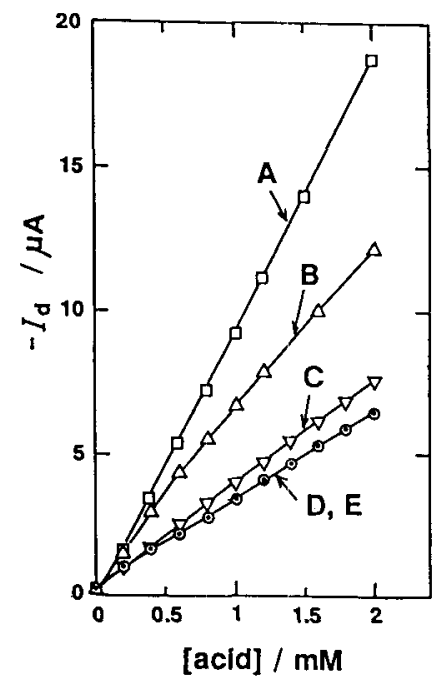

Fig. 5 Polarographic reduction wave height as a function of added acid concentration for the solutions of 0.125 $\mathrm{MNaClO}_{4}+0.025 \mathrm{M} \mathrm{KlO}_{3}$ with addition of $\mathrm{HCOO}_{4}(\mathrm{~A}), \mathrm{HCOOH}(\mathrm{B})$, and $\mathrm{CH}_{3} \mathrm{COOH}(\mathrm{C})$, and $0.125 \mathrm{M} \mathrm{KI}+0.025 \mathrm{M} \mathrm{KIO}_{3}$ with $\mathrm{HClO}_{4}$ (D) and $\mathrm{CH}_{3} \mathrm{COOH}(\mathrm{E})$.

depresses the liberation, and $\left[\mathrm{KIO}_{3}\right]$ does not influence the reaction in the concentration region as plotted. These results suggest that the $[\mathrm{KOH}]$ determine the rate of neutralization and $[\mathrm{KI}]$ significantly affect the rate process of the iodine liberation.

The reaction kinetics of eq. (1) is known as a typical fast reaction, whose reaction rate, $v$, has been represented by eq.(6) 11-13),

$$
v=k\left[\mathrm{H}^{+}\right]^{2}\left[\mathrm{IO}_{3}^{-}\right]\left[\mathrm{I}^{-}\right]^{2}, \quad k=3.0 \times 10^{8} \mathrm{M}^{-4} \quad--(6)
$$

The rate process, however, could not be ana lyzed for our competitive reaction, because the irreversible iodine liberation is mainly proceed by the acid having localized high concentration during the mixing of the acid and the alkaline $\mathrm{KI}+\mathrm{KIO}_{3}$ solution. Since convective condition during the mixing affects the amount of iodine liberation, the quantitative analysis of the competitive reaction kinetics did not succeed. However,

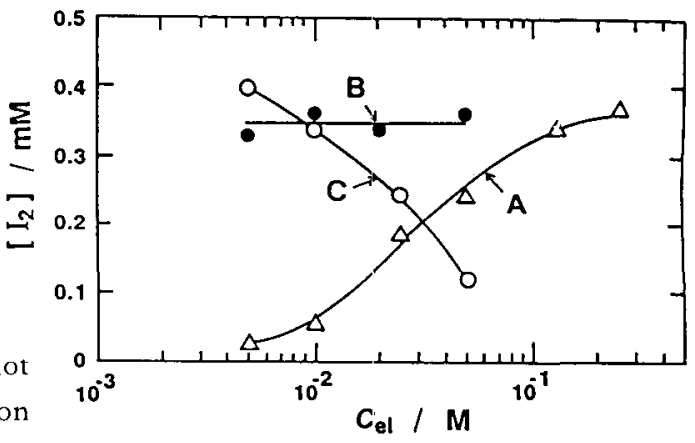

Fig. 7 Effects of electrolyte concentrations on the iodine concentration liberated by added acid( $\left.1 \mathrm{mM} \mathrm{HClO}_{4}\right)$ in $\mathrm{KI}+\mathrm{KIO}_{3}+\mathrm{KOH}$ solution systems. The current was measured at $-0.7 \mathrm{~V}$ by the constant potential method. (A) 0.025 $\mathrm{M} \mathrm{KIO}_{3}+0.010 \mathrm{M} \mathrm{KOH}+c_{\mathrm{el}} \mathrm{KI}$, (B) $0.125 \mathrm{M} \mathrm{KI}$ $+0.010 \mathrm{M} \mathrm{KOH}+c_{\mathrm{el}} \mathrm{KIO}_{3}$, (C) $0.125 \mathrm{M} \mathrm{KI}+0.025$ $\mathrm{M} \mathrm{KIO}_{3}+c_{\mathrm{el}} \mathrm{KOH}$.

the apparently linear relationship between $I_{\mathrm{d}}$ and [acid] as shown in Fig. 6(b) suggests that the amount of added acid can be detected by the amperometric method in the $\mathrm{KI}+\mathrm{KIO}_{3}+\mathrm{KOH}$ solution system. The localized accumulation of acid can be expected to occur at the gassolution-electrode interface of the gas sensor, therefore the acidic gases can be detected by the sensor using alkaline $\mathrm{KI}+\mathrm{KIO}_{3}$ solution ${ }^{3)}$. The alkaline additive is useful to stabilize the 
iodine-iodate solution for the acidic gas sensor.

The solution containing $0.025 \mathrm{M} \mathrm{NH}_{4} \mathrm{OH}$ with

$0.125 \mathrm{M} \mathrm{KI}+0.025 \mathrm{M} \mathrm{KIO}_{3}$ showed similar iodine liberation to that in the solution containing $\mathrm{KOH}$ instead of $\mathrm{NH}_{4} \mathrm{OH}$. The other hand, the addition of a weak acid into $\mathrm{KI}+\mathrm{KIO}_{3}+\mathrm{KOH}$ solution showed significantly lower liberation of iodine than that of strong acid. These results suggest that the neutralization proceeds between strong acid(or alkaline) and weak alkaline(or acid) as fast as strong acidalkaline, however, the iodine liberation induced by the weak acid is slower than that by the strong acid. These reaction characteristics will be applicable for a selective detection of acidic gases having different dissociation property.

\section{CONCLUSIONS}

Cathodic reactions of halide-halate and halate systems have been characterized as acid sensitive electrode reactions by polarography.

The polarographic wave heights with bromate and iodate reductions are proportional to the amount of added acid, which is attributed to the reaction, $\mathrm{XO}_{3}^{-}+6 \mathrm{H}^{+}+6 \mathrm{e}^{-} \rightarrow \mathrm{X}^{-}+3 \mathrm{H}_{2} \mathrm{O}(\mathrm{X}=$ $\mathrm{Br}, \mathrm{I})$, whose rate is controlled by the diffusion of the hydrogen ions.

In the iodide-iodate solutions, iodine is liberated by the addition of acid, $5 \mathrm{I}^{-}+\mathrm{IO}_{3}^{-}+$ $6 \mathrm{H}^{+} \rightarrow 3 \mathrm{I}_{2}+3 \mathrm{H}_{2} \mathrm{O}$, whose cathodic current of iodine reduction, $\mathrm{I}_{2}+2 \mathrm{e}^{-} \rightarrow 2 \mathrm{I}^{-}$, is proportional to amount of the added acid.

In the alkaline $\mathrm{KI}+\mathrm{KIO}_{3}$ solutions, iodine is also proportionally liberated with the addition of acid, whose mechanism was discussed from competitive reactions between the neutralization and the iodine liberation proceeded during the mixing process of the added acid and the alkaline $\mathrm{KI}+\mathrm{KIO}_{3}$ solution. From these reaction properties, it is suggested that the $\mathrm{KI}+$ $\mathrm{KIO}_{3}$ solution involving a slightly amount of alkaline additive is useful for an electrolyte of the amperometric acidic gas sensor.

For the amperometric acidic gas sensor, solutions of $\mathrm{I}^{-}+\mathrm{IO}_{3}^{-}, \mathrm{I}^{-}+\mathrm{BrO}_{3}^{-}, \mathrm{IO}_{3}^{-}$and $\mathrm{BrO}_{3}^{-}$ can be used as acid sensitive electrochemical reaction systems. In these systems, $\mathrm{I}^{-}+\mathrm{IO}_{3}^{-}$ system is the best one, because it has the most positive potential domain for the acid sensitive cathodic reaction, which has advantage to eliminate interference with oxygen reduction.

It was found that a slightly amount of alkaline additive in $\mathrm{I}^{-}+\mathrm{IO}_{3}^{-}$solution is effective to stabilize the iodine liberation by carbon dioxide in the atmosphere during the preparation of sensor solution. The alkaline additive is also useful for a selective acidic gas sensing without interference of carbon dioxide.

\section{REFERENCES}

1) T. Ishiji and K. Takahashi, Sens. Actuators, B1 3-14,583(1993).

2) T. Ishiji and K. Takahashi, Anal. Chem., 65 , 2736(1993).

3) T. Ishiji and K. Takahashi, Denki Kagaku, $56,1178(1990)$.

4) A.J. Downs and C.J. Adams, in Comprehensive Inorganic Chemistry (Edited by J.C. Bailer, Jr., et al. ) Vol. 2, pp. 1432-1434, Pargamon Press, Oxford (1973).

5) P.G. Desideri, L. Lepri and D. Heimler, in Encyclopedia of Electrochemistry of the Elements (Edited by A.J. Bard), Vol. 1, pp. 120-122, Marcel Dekker, New York (1973).

6) I.M. Kolthoff and J. Jordan, J. Am. Chem. Soc., 75, 1571(1953).

7) I.M. Kolthoff and J.J. Lingaine, Polarography, Vol. 2, pp. 576-577, Interscience Pub., New York (1952).

8) E.F. Orlemann and I.M. Kolthoff, J. Am. Chem. Soc., 64, 1044(1942).

9) A.F.M. Barton and G.A. Wright, J. Chem. Soc. (A), 1968, 1747 (1968).

10) A. Indelli, G. Nolan, Jr. and E.S. Amis, J. Am. Chem. Soc., 82,3233(1960).

11) International Critical Tables of Numerical Data, Physics, Chemistry and Technology, Vol. VII, p. 149, McGraw-Hill Book Co., New York (1930).

12) S. Dushman, J. Phys. Chem., 8, 453(1904).

13) A. Skrabel, Monatsh., 35,1157(1914). 